Haller had recognized migmatite domes, tongueshaped migmatite bodies, sheets, mushroom-shaped masses and migmatite complexes formed where migmatites of several types coalesce.

Dr. Haller referred to the intimate connexion between migmatization and regional metamorphism and showed that, just as in the Scottish Caledonides, the motamorphic zones cut across the fold structure and that the thermal changes outlasted the deformation of the superstructure.

Prof. B. C. King gave an account of the pattern of metamorphism in central and western Uganda, where in general there is a progressive increase in motamorphism on descending the stratigraphical succession.

There is also, Prof. King showed, a broad corrolation between grade of metamorphism and degree of duformation. A third factor is the proximity of granite. The occurrence of such minerals as cordierite and andalusite and the facts outlined above suggest that the regional metamorphism may well bo of Buchan type, though Prof. King did not specifically state this.

Prof. King provided an especially interesting account of the reactivation of basement rocks during later cycles. Ho suggested that the fundamental control of motamorphism was a rise in the geothermal gradient in the central parts of what was originally a basin of deformation and latterly an orogenic belt.

Dr. N. Rast discussed the relationship between deformation and regional metamorphism in the Dalradian rocks of Scotland. He showed that two peaks of regional metamorphism could be identified, the earlier of which accompanied the second of the three main phases of deformation, while the later uccurred between the second and third folding phases. Dr. Rast suggested that chemical equilibrium may be more readily reached when tectonic movement accompanied metamorphism and that under static conditions, at least in the lower grades of metamorphism, a very limited migration of material occurs. $\mathrm{He}$ directed attention to the episodic nature of the Dalradian metamorphism and to recent work pointing to comparable polymetamorphism in the Alps and Pyrenees.

Prof. J. Sutton discussed rather similar relation. ships near the margin of migmatite complexes of Caledonian and Pre-Cambrian age in north-west Scotland. One feature is the patchy development of metamorphic change in the outermost parts of the areas affected. A close relationship between the onset of metamorphism and the local intensity of deformation is observed in both regions which rein. forces one of the points made by Dr. Rast. Both the Laxfordian and the Caledonian complexes are bounded by rather sharp transition zones only a few kilometres in width beyond which the pre-existing rocks rotain their old minerals and structuros. Within the com. plexes a striking feature is the way in which deformation gradually obliterates the discordance between originally cross-cutting structures. Dr. R. W. Rutland described some foatures of the Caledonian chain in Norway a feature of which is the development of nappes of high-grade crystalline rocks. Dr. J. M. Hancock suggested that examination of the postorogenic sediments such as the old Red Sandstone might throw light on the controversial question of tho depth of cover during regional metamorphism. As a large number of Fellows of the Society took part in the discussion, a number of contributions have nocessarily been omitted from this summary.

J. SUTTON

\title{
INDIAN SEMINAR ON AERONAUTICAL SCIENCES
}

\begin{abstract}
A
SEMINAR in aeronautical sciences was organized by the National Aeronautical Laboratory, Bangalore, under the auspices of the Council of Scientific and Industrial Research (India) and was held during November 27-December 2. The seminar was inaugurated by the Governor of Mysore and presided over by Prof. M. S. Thacker, director-general of the Council of Scientific and Industrial Research.

More than 250 delegates, including twenty delegates from foreign countries, namely, Australia, France, Holland, Japan, the United Kingdom and the United States, attended the seminar. The delegates were welcomed by Dr. I'. Nilakantan, director of the National Aeronautical Laboratory. The technical sessions of the seminar covered several fields of aeronautical interest.

Indian activity in the field of aviation is mainly concentrated at Bangalore, where Hindustan Aircraft, Ltd., has factories employing 18,000 people. This firm has produced under licence a large number of British-designed aircraft and aero-engines, and the first flight took place recently of the $H F^{\prime}-24$, a supersonic fighter of the firm's own design.

There is also an excellent Aeronautical Engineering Department, under Prof. Satish Dhawan, at the Indian Institute of Science, Bangalore. This Institute, the director of which is Dr. Bhagavantam, the scientific adviser to the Ministry of Defence, is very interesting to a visitor, as demonstrating the
\end{abstract}

value of an entirely postgraduate teaching and research institution specializing in the basic physical and chemical sciences and their applications.

The numerous defonce laboratories in Bangaloro include the Acronautical Development Establishment under Dr. Mediratta. To all this previously existing aeronautical activity has now been added the important and rapidly developing National Aeronautical Laboratory under the Council for Scientific and Industrial Research. The seminar therefore gave a valuable opportunity to visitors to inspect much of the most important Indian activity in the aeronautical sciences, as well as to hear lectures on thoso subjects.

The session on aviation meteorology was presided over by Dr. P. R. Krishna Rao, director-general of observatories, India. The main topic discussed was wind structure at high altitudes, particularly in and around India, and its influence on air navigation. The session on aircraft structure and materials was presided over by Dr. V. M. Ghatage, doputy general manager, Hindustan Aircraft, Ltd., and was devoted to creep, fatigue and thermal effects. Prof. S. Dhawan, and also Prof. R. Kawamura of the University of Tokyo, presided over the sessions on aerodynamics. and papers on formation and stability of shock waves, hypersonic aerodynamics and approximation in transonic flows were presented. The highlights of the session were major surveys on aerodynamic noise by Prof. M. J. Lighthill, director, Royal Aircraft Estab- 


\section{№. 4816 February 17, $1962 \quad$ N A T U R E}

lishment (U.K.) and Mr. Arthur A. Regier, National Aeronautics and Space Administration (U.S.A.). Prof. Lighthill, and also Prof. P. L. Bhatnagar, of the Indian Institute of Science, presided over the sessions on fluid mechanics, and interesting papers were presented on flow in bent pipes, transition, the nature of turbulence, boundary layer problems in hypersonic flows and models for plasma oscillations. Dr. Frank L. Wattendorf, director, Advisory Group for Aeronautical Research and Development (NATO), presided over the session on wind-tunnel design and testing, aircraft propulsion and flight research. Papers were presented on wind-tunnel design problems, particularly at high subsonic and transonic speeds. Particular interest was shown in a report by $\mathrm{Mr}$. F. W. Hooton, of the Aeronautical Research Laboratories, Australia, on the formation of a flight research group in his laboratories. Prof. S. V. C. Aiya, of the Indian Institute of Science, presided over the session on aviation electronics, and interesting papers were presented, of which Mr. W. A. Johnson's paper on recent researches done at the Royal Aircraft Establishment in the field of aviation electronics, and that of Mr. L. R. Lucassen, National Aero- and Astro. nautical Research Institute, Holland, on an instationary method for measuring antennæ radiation patterns of the Fokker-27 in flight, evoked considerable interest.

On the last night, a banquet was arranged at the Century Club, Bangalore. Dr. P. Nilakantan proposed a toast to "The Delegates", and Prof. Lighthill, replying to the toast, proposed a toast to "The National Aeronautical Laboratory". Several of the foreign delegates spoke expressing their personal sentiments, congratulating the National Aeronautical Laboratory on holding the seminar. The final session terminated with a vote of thanks by Dr. Y. V. G. Acharya to all delegates and the staff of the National Aeronautical Laboratory for their valuable cooperation in making the seminar a success.

\section{UNITY IN THE ELECTRICAL INDUSTRY}

$\mathrm{T}$ HE title chosen by Mr. G. S. C. Lucas for his presidential address, delivered before the Institution of Electrical Engineers on October 5, was "Unity in the Electrical Industry".

After a brief reference to the forty-five years which he had himself spent in the industry, Mr. Lucas proceeded to review from several different points of view the changing pattern of the industry over the past half-century, to demonstrate a certain unity and continuity in its development, and to derive from these some inferences as to the pattern for the future.

Its man-power being the industry's most important asset, Mr. Lucas began his review by a survey of the growth and deployment of the scientific and technical personnel of the electrical industry over the period 1925-60. From the membership records of the Institution of Electrical Engineers it was possible to estimate fairly accurately the number of professionally qualified electrical engineers active in the United Kingdom at any given time. A similar estimate could be made of those qualified by education and training but who at the time had not achieved full professional status.

Data from which the numbers of technicians can be estimated are less readily available. The educa. tional qualifications of technicians are normally derived from National and Higher National Certificate courses or from City and Guilds courses, but a substantial fraction of Higher National Certificate holders have qualified for corporate membership of the Institution of Electrical Engineers and thus fall in the professional group. In computing the numbers of technicians it has been assumed that 45 per cent of all who sat for the Higher National Certificate finally qualified for Graduate membership of the Institution. An appropriate correction has been applied for deaths and retirements, and it is further assumed that 20 per cent have gone abroad. The progressive totals derived from these computations together with the figures for professional electrical engineers are given in Table 1.

Mr. Lucas directed particular attention to the rapid rise in the number of technicians, a factor not always taken into account in assessing our man-power resources. In a paper entitled "Recruitment of Pro-

\begin{tabular}{|c|c|c|c|c|c|}
\hline \multirow{4}{*}{$\begin{array}{l}\text { Professional man-power } \\
\text { Teehnician man-power: } \\
\text { National Certificate } \\
\text { City and Guilds }\end{array}$} & \multicolumn{3}{|c|}{ Table } & & \\
\hline & 1930 & 1940 & 1950 & 19 & 18 \\
\hline & 8,300 & 14,250 & 24,000 & 30,000 & 38,000 \\
\hline & $\begin{array}{l}1,960 \\
2,360\end{array}$ & $\begin{array}{l}8,960 \\
9,150\end{array}$ & 22,600 & $\begin{array}{l}36,500 \\
23,200\end{array}$ & $\begin{array}{l}69775 \\
257000\end{array}$ \\
\hline & & & 42,600 & 9,700 & \\
\hline
\end{tabular}

fessional Electrical Engineers", read before the Institution in 1958 he had emphasized the increasing importance of the technician to the electrical industry, pointing out that technicians hold posts of responsibility at all levels between that of the craftsman and that of the professional electrical engineer. He had expressed the opinion that new fields of activity for technicians were opening up with the development of design methods based on computers and analysers and of new methods of presentation of design information applicable to the electronic control of machine tools. The time had come when technician qualifications should be recognized as something honourable and worth while in their own right. It was to be hoped, he said, that before long the existing confusion resulting from the use of the National Certificate route as a channel for professional as well as for technician qualifications would come to an end.

Proceeding to a comparison of British electrical engineering man-power with Russian and American, Mr. Lucas gave a table of totals and of numbers per ten thousand of population for the United Kingdom from 1930 together with the corresponding data for the U.S.S.R. and the United States, in so far as these were available. From this analysis Mr. Lucas concluded that, in proportion to our population, we have in Great Britain a good body of well-educated elec. trical engineers and electrical technicians. He went on to say, however, that the differences in total man-power do not alone explain the failure of Great Britain, in many instances, to exploit quickly and effectively scientific discoveries and inventions which have originated here. The trouble, he believed, lay not so much in the smaller total forces of technical personnel which we could deploy as in their dispersal. Our technical resources were being dissipated in repetition of the development of the same apparatus and devices by separate research, development and 